\title{
Understanding and reducing deleterious defects in the metastable alloy GaAsBi
}

\author{
Guangfu Luo ${ }^{1}$, Shujiang Yang ${ }^{1}$, Glen R Jenness ${ }^{2}$, Zhewen Song ${ }^{1}$, Thomas F Kuech ${ }^{3}$ and Dane Morgan ${ }^{1}$ \\ Technological applications of novel metastable materials are frequently inhibited by abundant defects residing in these \\ materials. Using first-principles methods, we investigate the defect thermodynamics and phase segregation in the technologically \\ important metastable alloy GaAsBi. Our calculations predict defect energy levels in good agreement with those from numerous \\ previous experiments and clarify the defect structures giving rise to these levels. We find that vacancies in some charge states \\ become metastable or unstable with respect to antisite formation, and this instability is a general characteristic of zincblende \\ semiconductors with small ionicity. The dominant point defects that degrade the electronic and optical performances
} are predicted to be $A s_{G a}, B i_{G a}, A s_{G_{a}}+B_{A s}, B i_{G a}+B_{A s}, V_{G a}$ and $V_{G_{a}}+B_{A s}$, of which the first four and last two defects are minority-electron and minority-hole traps, respectively. $V_{\mathrm{Ga}}$ is also observed to have a critical role in controlling metastable $\mathrm{Bi}$ supersaturation by mediating Bi diffusion and clustering. To reduce the influences of these deleterious defects, we suggest shifting the growth away from an As-rich condition and/or using hydrogen passivation to reduce the minority-carrier traps. We expect this work to aid in the applications of GaAsBi for novel electronic and optoelectronic devices and to illuminate the control of deleterious defects in other metastable materials.

NPG Asia Materials (2017) 9, e345; doi:10.1038/am.2016.201; published online 27 January 2017

\section{INTRODUCTION}

The metastable alloy GaAsBi has been intensely studied since its first successful fabrication by metalorganic vapor phase epitaxy in $1998^{1}$ and by molecular beam epitaxy in $2003^{2}$ owing to three key advantages over other GaAs-based compounds. First, Bi atoms reduce the band gap much more effectively than other alloying elements, such as In $(\approx 83 \mathrm{meV}$ per $\mathrm{Bi} \%$ versus $\approx 15 \mathrm{meV}$ per $\mathrm{In} \%) .{ }^{3}$ Second, $\mathrm{Bi}$ incorporation dramatically decreases the temperature dependence of the electronic properties. For instance, a GaAsBi film with $2.6 \% \mathrm{Bi}$ has a temperature coefficient of the band gap only $1 / 3$ of that of GaAs near room temperature. ${ }^{4}$ This property can lead to the realization of temperature-insensitive devices, ${ }^{5}$ as confirmed in a study of GaAsBi-based laser diodes, ${ }^{6}$ and benefits a number of technologies. Third, Bi atoms strongly increase the spin-orbit splitting of $\mathrm{GaAsBi}$, and for Bi contents near $10 \%$, it is expected to totally suspend one type of Auger recombination, ${ }^{3,5}$ which induces the serious 'efficiency droop' in high-energy light-emitting diodes and laser diodes. These advantages indicate that GaAsBi would provide a major improvement in many semiconductor devices as long as high-quality materials with a significant Bi content can be obtained.

However, Bi has a very low solubility in GaAs; the incorporation of a large Bi content $(\sim 10 \%)$ with low defects and without phase segregation is especially challenging. ${ }^{7}$ In the usual growth temperature range of $\mathrm{GaAs}, 500-600^{\circ} \mathrm{C}$, the $\mathrm{Bi}$ incorporation is nearly zero, which has been confirmed by both experiments ${ }^{8}$ and theoretical claculations. ${ }^{9}$ To enhance the $\mathrm{Bi}$ incorporation, growth temperatures as low as $300-400{ }^{\circ} \mathrm{C}$ are widely used to decelerate the growth dynamics that lead to low $\mathrm{Bi}$ incorporation. However, the low growth temperature also induces numerous defects, which result in short carrier lifetimes and low photoluminescence intensity. ${ }^{10,11}$ Additionally, a previous theoretical study ${ }^{12}$ has shown that the dynamic processes associated with As substituting $\mathrm{Bi}$, which limits $\mathrm{Bi}$ incorporation, are still extremely rapid at low temperatures, for example, $<10^{-6} \mathrm{~s}$ at $320^{\circ} \mathrm{C}$. Thermal annealing has been used to reduce the defects, but the incorporated $\mathrm{Bi}$ atoms often segregate and form Bi-rich clusters. ${ }^{13}$ These defect-related issues have become a bottleneck in the successful applications of GaAsBi. For instance, to date, GaAsBi-based laser diodes require a threshold current density $\left(2-10 \mathrm{kA} \mathrm{cm}^{-2}\right)^{6,14-16}$ that is approximately an order of magnitude higher than that of typical InGaAs-based laser diodes $\left(0.2-0.5 \mathrm{kA} \mathrm{cm}^{-2}\right)$.

Here we address the following essential questions related to the defects in GaAsBi: What are the primary intrinsic point defects, and how do they interact to form pair defects under equilibrium conditions? How do the defects affect the minority-carriers? Which defects mediate the formation of Bi-rich clusters during thermal annealing? Finally, how can one reduce the deleterious effects of the dominant defects? Our results are predominantly based on the

${ }^{1}$ Department of Materials Science and Engineering, University of Wisconsin-Madison, Madison, WI, USA; ${ }^{2}$ Department of Chemistry, University of Wisconsin-Madison, Madison, WI, USA and ${ }^{3}$ Department of Chemical and Biological Engineering, University of Wisconsin-Madison, Madison, WI, USA

Correspondence: Professor D Morgan, Department of Materials Science and Engineering, University of Wisconsin-Madison, Room 244, 1509 University Avenue, Madison, WI 53706, USA.

E-mail: ddmorgan@wisc.edu

Received 5 September 2016; revised 7 November 2016; accepted 7 November 2016 
thermodynamic properties of defects, which are expected to provide a useful guide to many aspects of defect behavior, even under non-equilibrium conditions. Additionally, we will qualitatively discuss non-equilibrium effects when the equilibrium results become invalid.

\section{MATERIALS AND METHODS}

In this paper, we examine six point defects: $V_{\mathrm{Ga}}, V_{\mathrm{As}}, \mathrm{As}_{\mathrm{Ga}}, \mathrm{Ga}_{\mathrm{As}}, \mathrm{Bi}_{\mathrm{As}}$ and $\mathrm{Bi}_{\mathrm{Ga}}$. The interstitial defects of $A s$ and $G a$ are known for their high formation energies in $\mathrm{GaAs}^{17,18}$ and are therefore excluded, as is the Bi interstitial. To determine how the dominant point defects interact with each other, we further examine thirteen pair defects, each consisting of two nearestneighbor point defects. Motivated by the findings on pair defects, we examine eight clusters involving Bi defects with and without vacancies to explore the formation of Bi-rich clusters. Finally, we investigate eight defects involving $\mathrm{H}$ to examine the effects of hydrogen passivation.

We carry out $a b$ initio calculations using density functional theory, as implemented in the Vienna $a b$ initio Simulation Package. ${ }^{19}$ An energy cutoff of $400 \mathrm{eV}$ is set to the plane-wave basis set, and the following projectoraugmented wave potentials are utilized: Ga_GW $\left(4 s^{2} 4 p^{1}\right)$ for Ga, As_GW $\left(4 s^{2} 4 p^{3}\right)$ for As, Bi_d_GW $\left(5 d^{10} 6 s^{2} 6 p^{3}\right)$ for Bi and H_GW $\left(1 s^{1}\right)$ for H. These GW potentials generally give better properties for excited electronic states than the standard density functional theory potentials, and they are therefore appropriate for our defect calculations involving charge transfer to excited states. The HSE $06^{20}$ hybrid functional is used to correctly describe the band gap. The predicted band gap of the bulk GaAs using HSE06 is $1.38 \mathrm{eV}$, which is consistent with the experimental value of $1.42 \mathrm{eV}$ at $300 \mathrm{~K} .{ }^{21}$ To describe the strong special relativity effects in the $\mathrm{Bi}$ atom, the spin-orbit coupling is included for the calculations involving Bi. The predicted spin-orbit splitting at the $\Gamma$ point is $0.39 \mathrm{eV}$ for bulk GaAs, which is in excellent agreement with the experimental value of $0.34 \mathrm{eV}$ at $300 \mathrm{~K}^{21}$ In Supplementary Figure S1, we demonstrate the importance of using both HSE06 and spin-orbit coupling by showing the notable differences in the defect formation energies using different methods. In our HSE06 calculations, the supercell size is $2 \times 2 \times 2$, with a volume of $11.2^{3} \AA^{3}$, and the k-point sampling is a $4 \times 4 \times 4$ MonkhorstPack grid. The ab initio method proposed by Freysoldt, Neugebauer and Van de Walle (FNV) ${ }^{22}$ is adopted to remove the image charge interaction and adjust the potential alignment between the perfect and defected structures. Our tests suggest that the error in the defect formation energy after the FNV correction is limited to approximately $0.1 \mathrm{eV}$ (Supplementary Figure S2). Symmetry is broken to allow a possible Jahn-Teller distortion around the defects. To automatically generate the initial structures, manage the workflow and postprocess the results, the high-throughput computational tool, MAterials Simulation Toolkit ${ }^{23}$ is used. Note that the three major factors, ${ }^{24}$ namely, correct description of the band gap, proper removal of the image charge interaction and proper potential alignment, are critical to obtain reliable defect formation energies. Inadequate treatment of these three factors in previous studies of bulk GaAs resulted in scattered data (Supplementary Figure S3).

Table 1 Chemical potential $\mu(\mathrm{eV})$ of $\mathrm{Bi}$, As and $\mathrm{Ga}$ under As-rich, Ga-rich and intermediate conditions

\begin{tabular}{llll}
\hline & As-rich & Ga-rich & Intermediate \\
\hline$\mu_{\mathrm{Bi}}$ & -6.00 & -6.00 & -6.00 \\
$\mu_{\mathrm{As}}$ & -5.93 & -6.88 & -6.40 \\
$\mu_{\mathrm{Ga}}$ & -4.60 & -3.65 & -4.13 \\
\hline
\end{tabular}

$\mu_{\mathrm{Bi}}$ is the total energy per atom of the rhombohedral $\mathrm{Bi}$ metal, as a significant number of $\mathrm{Bi}$ layers or droplets exist on the film surface under usual growth conditions. ${ }^{12} \mu_{\mathrm{As}}\left(\mu_{\mathrm{G}}\right)$ under the As-rich (Ga-rich) condition equals the total energy per atom of the hexagonal As (orthorhombic Ga) bulk. Sum of $\mu_{\mathrm{Ga}}$ and $\mu_{\mathrm{As}}$ under the same condition equals the total energy per chemical formula of GaAs bulk. The absolute difference of $\mu_{\mathrm{Ga}}$ or $\mu_{\mathrm{As}}$ between the As- and Ga-rich conditions equals the standard formation enthalpy of GaAs, and our theoretical value of $0.95 \mathrm{eV}$ is in good agreement with a recent experimental measurement of $0.91 \mathrm{eV} .{ }^{25} \mu$ of the intermediate condition is defined as the average value of the As- and Ga-rich conditions.
The defect formation energy $E_{\mathrm{f}}$ of a defect $A_{B}$ (atom $A$ on host site $B$ ) with a charge state $q$ is defined in Equation (1), ${ }^{24}$

$$
\begin{aligned}
E_{\mathrm{f}}\left(A_{B}^{q}, E_{\mathrm{F}}\right) \equiv & E_{\mathrm{tot}}\left(A_{B}^{q}\right)+E_{\mathrm{FNV}}\left(A_{B}^{q}\right)-E_{\mathrm{tot}}(\mathrm{GaAs})+\mu_{B}-\mu_{A} \\
& +q\left[E_{\mathrm{VBM}}(\mathrm{GaAs})+E_{\mathrm{F}}\right]
\end{aligned}
$$

where $E_{\text {tot }}\left(A_{B}^{q}\right)$ and $E_{\text {tot }}(\mathrm{GaAs})$ are the total internal energies of the system with defect $A_{B}^{q}$ and the perfect bulk GaAs, respectively; $E_{\mathrm{FNV}}, E_{\mathrm{VBM}}$ and $E_{\mathrm{F}}$ are the FNV correction, valence band maximum (VBM) energy and Fermi energy relative to the VBM energy, respectively; the chemical potentials $\mu_{X}$ for $X=\mathrm{Bi}$, As and Ga at different conditions are summarized in Table 1. The lowest defect formation energy of a defect, $E_{\mathrm{f}}^{\mathrm{min}}$, is determined by the minimum value of different charge states,

$$
E_{\mathrm{f}}^{\min }\left(A_{B}, E_{\mathrm{F}}\right) \equiv \operatorname{Min}\left\{E_{\mathrm{f}}\left(A_{B}^{q}, E_{\mathrm{F}}\right)\right\} .
$$

Defect energy levels correspond to the $E_{\mathrm{F}}$ where the slope of $E_{\mathrm{f}}^{\min }$ changes and the levels are independent of the chemical potential. To explore the interaction between different defects, we define the binding energy, $E_{\mathrm{b}}$, of a complex defect by Equation (3).

$$
\begin{aligned}
E_{\mathrm{b}}\left(A_{B}+C_{D}, E_{\mathrm{F}}\right) \equiv & E_{\mathrm{f}}^{\min }\left(A_{B}+C_{D}, E_{\mathrm{F}}\right)-E_{\mathrm{f}}^{\min }\left(A_{B}, E_{\mathrm{F}}\right) \\
& -E_{\mathrm{f}}^{\min }\left(C_{D}, E_{\mathrm{F}}\right),
\end{aligned}
$$

where the complex defect $A_{B}+C_{D}$ consists of defects $A_{B}$ and $C_{D}$ bound together.

\section{RESULTS AND DISCUSSION}

\section{Metastability of defects involving vacancy}

Our first finding is that in certain charge states, when the formation energies are typically very high, the point and pair defects involving vacancy become metastable or unstable. This instability means that the cation and anion vacancies can transform between each other with the assistance of an antisite defect, a phenomenon that was first theoretically discovered for isolated $V_{\mathrm{As}}$ and $V_{\mathrm{Ga}}$ over 30 years ago. ${ }^{26,27}$ Table 2 shows that $V_{\mathrm{As}}$ can change to $V_{\mathrm{Ga}}+\mathrm{Ga}_{\mathrm{As}}$ at the 2and 3 - charge states and that $V_{\mathrm{Ga}}$ can change to $V_{\mathrm{As}}+\mathrm{As}_{\mathrm{Ga}}$ at the $1+$, $2+$ and $3+$ charge states. As we will show later in Figure 1a, these charge states correspond to $V_{\mathrm{As}}$ and $V_{\mathrm{Ga}}$ with high formation energies relative to the other charge states. Because $V_{\mathrm{As}}$ and $V_{\mathrm{Ga}}$ at the aforementioned charge states are metastable, one needs to directly examine the 'swapped' structures to reveal their greater stability, which possibly explains the disregarding of these swapped structures in recent studies of GaAs. ${ }^{18,28,29}$ The anion (cation) vacancy in the pair defects $V_{\mathrm{As}}+\mathrm{Bi}_{\mathrm{As}}, V_{\mathrm{Ga}}+\mathrm{Bi}_{\mathrm{Ga}}, V_{\mathrm{Ga}}+\mathrm{As}_{\mathrm{Ga}}$ and $V_{\mathrm{Ga}}+\mathrm{Bi}_{\mathrm{As}}$ at certain charge states can all undergo similar structural changes to a more stable form, with a cation (anion) vacancy and an antisite replacing the original vacancy. The three other pair defects, $V_{\mathrm{As}}+\mathrm{Bi}_{\mathrm{Ga}}, V_{\mathrm{As}}+\mathrm{As}_{\mathrm{Ga}}$ and $V_{\mathrm{Ga}}$ $+\mathrm{Ga}_{\mathrm{As}}$, can change to a more stable form at certain charge states by hopping the $\mathrm{Bi}$, As and $\mathrm{Ga}$ to the neighboring vacancy, respectively.

Experimental observation of the aforementioned metastability can be challenging because it occurs under conditions at which the defects have relatively high formation energies and therefore low concentrations, for example, an n-type doping condition for $V_{\mathrm{As}}$ and a p-type doping condition for $V_{\mathrm{Ga}}$. Nevertheless, a possible experimental observation of the change $V_{\mathrm{As}}+\mathrm{As}_{\mathrm{Ga}} \rightarrow V_{\mathrm{Ga}}$ was suggested in an early deep-level transient spectroscopic study, ${ }^{30}$ which claimed that the signal decrease of $V_{\mathrm{As}}+\mathrm{As}_{\mathrm{Ga}}$ was accompanied by the signal increase of $V_{\mathrm{Ga}}$ during the treatment of n-type GaAs using ultrasonic vibration. To explore the generality of vacancy metastability in compound semiconductors, we examine the anion vacancy of 12 zincblende binary compounds, including $\mathrm{ZnO}, \mathrm{SiC}$ and $10 \mathrm{III}-\mathrm{V}$ compounds. The results indicate that the metastability is closely related to ionicity: all the examined compounds with an ionicity of $<0.5$ undergo a similar change as $V_{\mathrm{As}}$ in GaAs (Supplementary Table S1). 


\section{Formation energy of point and pair defects}

Figure 1a shows the defect formation energy of the point defects under the As-rich condition, which is widely employed by providing an excessive amount of As reactant in the growth chamber. The influence of other chemical potentials on the defect formation energy will be discussed at the end of this paper. The aforementioned metastability significantly changes the properties of $V_{\mathrm{Ga}}$ and $V_{\mathrm{As}}$ under the p- and n-type doping conditions, respectively. The dominant defects are $\mathrm{As}_{\mathrm{Ga}}{ }^{2+}, \mathrm{Bi}_{\mathrm{Ga}}{ }^{2+}$ and $\mathrm{Bi}_{\mathrm{As}}{ }^{0}$ in the p-type films, whereas the dominant defects are $V_{\mathrm{Ga}}{ }^{3-}$ and $\mathrm{Bi}_{\mathrm{As}}{ }^{0}$ in the n-type films. By contrast, $V_{\mathrm{As}}$ and $\mathrm{Ga}_{\mathrm{As}}$ have much larger formation energies and are expected to have insignificant concentrations at or near thermal equilibrium. Note that, although $\mathrm{Bi}_{\mathrm{As}}$ and $\mathrm{Bi}_{\mathrm{Ga}}$ do not have the lowest defect formation energy under most doping conditions, their non-equilibrium contents are expected to be dominant because of the significant (typically $>1 \%$ ) overall Bi content in most GaAsBi films.

Notably, under the condition $E_{\mathrm{F}}<0.21 \mathrm{eV}$, the equilibrium content of $\mathrm{Bi}_{\mathrm{Ga}}{ }^{2+}$ is predicted to be substantially more than that of $\mathrm{Bi}_{\mathrm{As}}{ }^{0}$. This prediction suggests that the usual assumption that the incorporated $\mathrm{Bi}$ primarily substitutes As owing to their chemical similarity does not hold under certain growth conditions. A previous growth of Bi-doped GaAs using the liquid-encapsulated Czochralski method indeed found a significant amount $(\sim 10 \%)$ of $\mathrm{Bi}$ in the form of $\mathrm{Bi}_{\mathrm{Ga}} \cdot{ }^{31}$ It is worth noting that another study ${ }^{32}$ estimated the maximum ratio of $\mathrm{Bi}_{\mathrm{Ga}}$ as only $\sim 5 \%$ of the total incorporated Bi atoms. That estimation was

Table 2 Structural changes of point and pair defects involving vacancy

\begin{tabular}{llll}
\hline Point defect & & \multicolumn{2}{c}{ Pair defect } \\
\cline { 3 - 4 } Reaction & $\mathrm{Q}_{f}$ & Reaction & $\mathrm{Q}_{f}$ \\
\hline$V_{\mathrm{As} \leftrightarrow V_{\mathrm{Ga}}+\mathrm{Ga}_{\mathrm{As}}}$ & $2-, 3-$ & $V_{\mathrm{As}}+\mathrm{Bi}_{\mathrm{As}} \leftrightarrow V_{\mathrm{Ga}}+\mathrm{Ga}_{\mathrm{As}}+\mathrm{Bi}_{\mathrm{As}}$ & $2-, 3-$ \\
& & $V_{\mathrm{As}}+\mathrm{Bi}_{\mathrm{Ga}} \leftrightarrow V_{\mathrm{Ga}}+\mathrm{Bi}_{\mathrm{As}}$ & $3-$ to 0 \\
& & $V_{\mathrm{As}}+\mathrm{As}_{\mathrm{Ga}} \leftrightarrow V_{\mathrm{Ga}}$ & $3-$ to 0 \\
& & $V_{\mathrm{Ga}}+\mathrm{Bi}_{\mathrm{Ga}} \leftrightarrow V_{\mathrm{As}}+\mathrm{As}_{\mathrm{Ga}}+\mathrm{Bi}_{\mathrm{Ga}}$ & $1+$ to 3+ \\
& & $V_{\mathrm{Ga}}+\mathrm{As}_{\mathrm{Ga}} \leftrightarrow V_{\mathrm{As}}+\mathrm{As}_{\mathrm{Ga}}+\mathrm{As}_{\mathrm{Ga}}$ & $1+$ to 3+ \\
& & $V_{\mathrm{Ga}}+\mathrm{Bi}_{\mathrm{As}} \leftrightarrow V_{\mathrm{As}}+\mathrm{Bi}_{\mathrm{Ga}}$ & $1+$ to 3+ \\
& & $V_{\mathrm{Ga}}+\mathrm{Ga}_{\mathrm{As}} \leftrightarrow V_{\mathrm{As}}$ & $1-$ to 3+ \\
& & &
\end{tabular}

$Q_{\mathrm{f}}$ is the total charge state of the initial and resulting defects when the forward change is favorable. The backward change is favorable at all the other charge states in the range of $[3-, 3+]$. based on a fitting of the theoretical structural expansion around $\mathrm{Bi}_{\mathrm{As}}$ and $\mathrm{Bi}_{\mathrm{Ga}}$ with experimental X-ray absorption spectra, and a fundamental parameter utilized was that the Bi-As bonds around $\mathrm{Bi}_{\mathrm{Ga}}$ are $0.15 \AA$ longer than the $\mathrm{Bi}-\mathrm{Ga}$ bonds around $\mathrm{Bi}_{\mathrm{As}}$. However, our calculations indicate that the aforementioned bond length difference varies dramatically with the charge state of $\mathrm{Bi}_{\mathrm{Ga}}$. Namely, the $\mathrm{Bi}$-As bonds around $\mathrm{Bi}_{\mathrm{Ga}}{ }^{2+}, \mathrm{Bi}_{\mathrm{Ga}}{ }^{+}$and $\mathrm{Bi}_{\mathrm{Ga}}{ }^{0}$ are $0.05,0.11$ and $0.15 \AA$ longer than the $\mathrm{Bi}-\mathrm{Ga}$ bonds around $\mathrm{Bi}_{\mathrm{As}}{ }^{0}$, respectively. The previous study therefore applied bond lengths, which were appropriate for only the structures of $\mathrm{Bi}_{\mathrm{Ga}}{ }^{0}$ and $\mathrm{Bi}_{\mathrm{As}}{ }^{0}$. If $\mathrm{Bi}_{\mathrm{Ga}}{ }^{2+}$ in the p-type films were considered, the fitting would yield a significantly higher fraction of $\mathrm{Bi}_{\mathrm{Ga}}$. Because $\mathrm{Bi}_{\mathrm{Ga}}$ possesses deep energy levels, which are significant carrier traps as discussed below, but isolated $\mathrm{Bi}_{\mathrm{As}}$ does not, further experimental verification of the Bi substitution sites under different growth conditions is a critical requirement.

To verify our results, we compare the predicted energy levels of the point defects with available experimental data in Figure 2. We find that the average deviation between our predictions and the experimental values is $0.06 \mathrm{eV}$, which is encouraging given the much larger deviation found in previous theoretical studies (Supplementary Figure S3). For the most extensively studied defect $\mathrm{As}_{\mathrm{Ga}}$, which

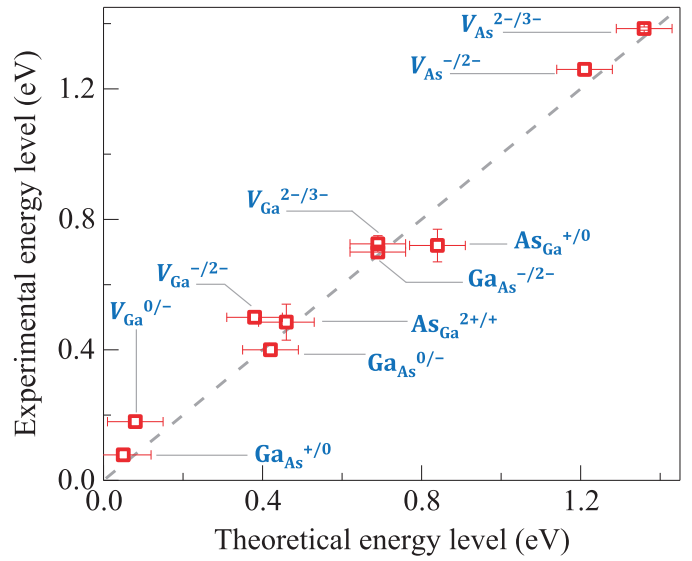

Figure 2 Comparison between defect energy levels obtained from experiments and predictions by this work. The error bars represent the range of different values of the experimental data ( $V_{\mathrm{Ga}}$ from refs $33,34, V_{\text {As }}$ from refs 35,36, $\mathrm{As}_{\mathrm{Ga}}$ from refs $31,37-39$ and $\mathrm{Ga}_{\mathrm{As}}$ from refs $40-42$ ) or the supercell convergence errors of the theoretical data.
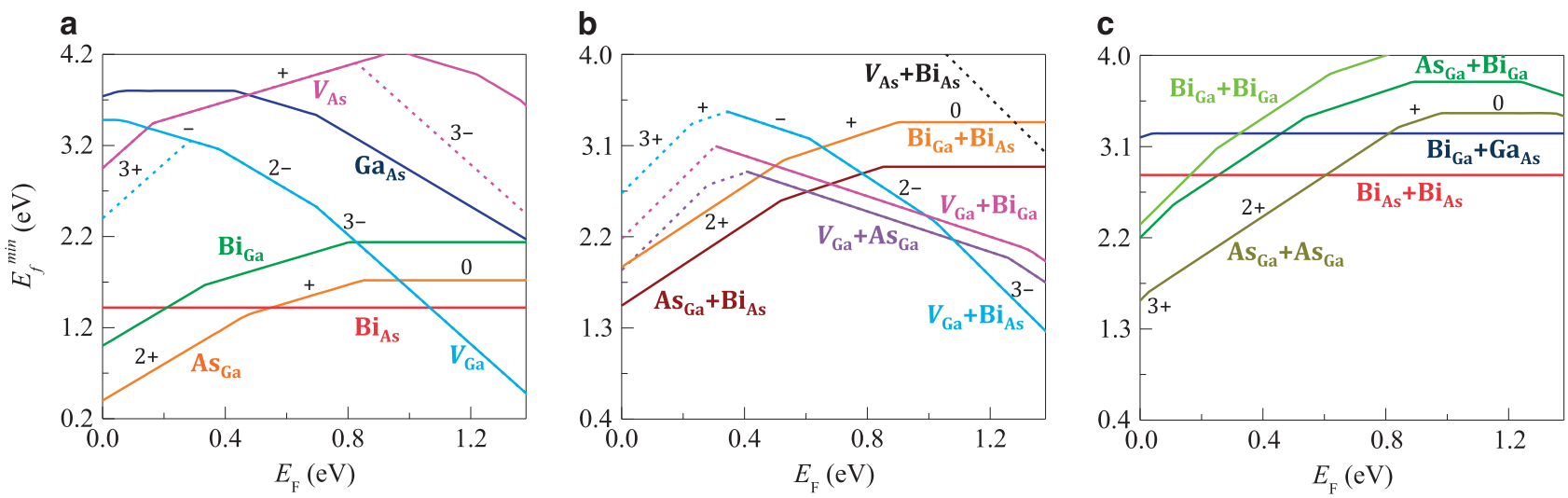

Figure 1 Lowest defect formation energy versus Fermi energy for (a) point defects and (b, c) pair defects under the As-rich condition. The dashed branches correspond to the stable swapped structures listed in Table 2 ; in (a), the metastable states of $V_{\mathrm{Ga}}$ and $V_{\mathrm{As}}$ are shown for reference. The results of the pair defects are plotted in two panels for easy visualization. 
corresponds to the EL2 peak in deep-level transient spectroscopic experiments, our predicted positions are 0.46 and $0.84 \mathrm{eV}$ for the $2+/+$ and $+/ 0$ energy levels, which agree reasonably well with the average experimental values of 0.49 and $0.72 \mathrm{eV}$, respectively.

Additionally, our results question the accuracy of earlier reports on the energy levels of $V_{\mathrm{As}}$ and $\mathrm{Bi}_{\mathrm{Ga}}$. As shown in Figure 2, the two energy levels of $V_{\text {As }}$ near the conduction band minimum were identified as $+/ 0$ and $0 /-$ by Saarinen et al. ${ }^{35}$ but $0 /-$ and $-/ 2-$ by Loualiche et al. ${ }^{33}$, both of which are different from our prediction of $-/ 2-$ and $2-13-$. Kunzer at al. ${ }^{31}$ conjectured that the energy levels of $\mathrm{Bi}_{\mathrm{Ga}}{ }^{2+/+}$ and $\mathrm{Bi}_{\mathrm{Ga}}{ }^{+/ 0}$ lie in the ranges of $0.72-0.77 \mathrm{eV}$ and $0.92-1.07 \mathrm{eV}$, respectively, which deviate significantly from our predictions of 0.33 and $0.80 \mathrm{eV}$, respectively.

Figures $1 \mathrm{~b}$ and $\mathrm{c}$ show the defect formation energies of the pair defects. We find that the dominant pair defects originate from the combinations of dominant point defects $\left(\mathrm{As}_{\mathrm{Ga}}, \mathrm{Bi}_{\mathrm{As}}, \mathrm{Bi}_{\mathrm{Ga}}\right.$ and $\left.V_{\mathrm{Ga}}\right)$. Under p-type conditions, the dominant pair defect is $\left(\mathrm{As}_{\mathrm{Ga}}+\mathrm{Bi}_{\mathrm{As}}\right)^{2+}$. Although $\left(\mathrm{As}_{\mathrm{Ga}}+\mathrm{As}_{\mathrm{Ga}}\right)^{2+, 3+}$ also has relatively low formation energies under p-type conditions, we will later show that two $\mathrm{As}_{\mathrm{Ga}}$ defects have a repulsive interaction under such conditions; thus the formation of the pair is unlikely. Under n-type conditions, the dominant pair defects are $\left(V_{\mathrm{Ga}}+\mathrm{Bi}_{\mathrm{As}}\right)^{3-}$ and $\left(V_{\mathrm{Ga}}+\mathrm{As}_{\mathrm{Ga}}\right)^{1-, 2-}$, both of which involve $V_{\mathrm{Ga}}$. It should be noted that the non-equilibrium growth of most GaAsBi films leads to much higher total $\mathrm{Bi}$ contents than the equilibrium values. To determine the potential influences of non-equilibrium conditions on Bi defects, we calculate the defect formation energies for a fixed total $\mathrm{Bi}$ content of $1 \%$, which is established by allowing the $\mathrm{Bi}$ chemical potential $\mu_{\mathrm{Bi}}$ to vary with $E_{\mathrm{F}}$, as required (see Supplementary Information $\mathrm{V}$ ). We find that five Bi defects: $\mathrm{Bi}_{\mathrm{As}}, \mathrm{Bi}_{\mathrm{Ga}}, \mathrm{Bi}_{\mathrm{Ga}}+\mathrm{Bi}_{\mathrm{As}}, \mathrm{Bi}_{\mathrm{As}}+\mathrm{Bi}_{\mathrm{As}}$ and $V_{\mathrm{Ga}}+\mathrm{Bi}_{\mathrm{As}}$ would have significant concentrations in certain regions of $E_{\mathrm{F}}$ (Supplementary Figure S4).

From the determinations above, we can now clarify the nature of the majority-carrier traps reported by recent deep-level transient spectroscopic experiments on GaAsBi. ${ }^{43}$ As listed in Table 3, the three experimental majority-electron traps in n-type films can be assigned to our predicted primary defect levels of $\left(V_{\mathrm{Ga}}+\mathrm{Bi}_{\mathrm{As}}\right)^{2-13-}, V_{\mathrm{Ga}}{ }^{2-13-}$ and $\left(V_{\mathrm{Ga}}+\mathrm{Bi}_{\mathrm{As}}\right)^{-12-}$, with an average deviation of $\sim 0.12 \mathrm{eV}$ between the experiments and this work. For the six majority-hole traps in p-type films, the three highest energy levels can be assigned to $\left\{\mathrm{Bi}_{\mathrm{Ga}}{ }^{+/ 0}\right.$, $\left.\mathrm{As}_{\mathrm{Ga}}{ }^{+/ 0},\left(\mathrm{As}_{\mathrm{Ga}}+\mathrm{Bi}_{\mathrm{As}}\right)^{+/ 0},\left(\mathrm{Bi}_{\mathrm{Ga}}+\mathrm{Bi}_{\mathrm{As}}\right)^{+/ 0}\right\},\left\{\mathrm{As}_{\mathrm{Ga}}{ }^{2+/+},\left(\mathrm{As}_{\mathrm{Ga}}+\mathrm{Bi}_{\mathrm{As}}\right)^{2+/+}\right.$, $\left.\left(\mathrm{Bi}_{\mathrm{Ga}}+\mathrm{Bi}_{\mathrm{As}}\right)^{2+/+}\right\}$ and $\mathrm{Bi}_{\mathrm{Ga}}{ }^{2+/+}$, with an average deviation of $\sim 0.04 \mathrm{eV}$ between the experiments and this work. As we will show later, the lowest defect level at $0.08 \mathrm{eV}$ could be assigned to Bi-rich clusters with vacancies, such as $V_{\mathrm{As}}+4 \mathrm{Bi}_{\mathrm{As}}$ and $V_{\mathrm{Ga}}+4 \mathrm{Bi}_{\mathrm{As}}$. The nature of the energy levels at 0.12 and $0.17 \mathrm{eV}$ is unclear, and they could be ascribed to unexplored complex defects and/or impurities in the films.

\section{Influences of defect energy levels on minority-carriers}

To identify the most deleterious defect energy levels to minoritycarriers, which are critical to the electron-hole recombination in optoelectronic devices, we show the strength of minority-carrier trapping as a function of the Fermi energy for each defect energy level in Figure 3. The trapping rate ${ }^{44}$ of the minority-electron (minority-hole) for a given defect energy level, $r_{\mathrm{e} \text {-trap }}\left(r_{\mathrm{h} \text {-trap }}\right)$, is determined by the product of three factors, namely, the defect concentration, $c_{\mathrm{d}}$, the non-occupancy fraction of the defect energy level for the electron (hole), $f_{\mathrm{e}, 1}\left(f_{\mathrm{h}, 1}\right)$ and the capture cross-section of the electron (hole), $\sigma_{\mathrm{e}}\left(\sigma_{\mathrm{h}}\right)$ :

$$
\begin{aligned}
& r_{e-\text { trap }}=c_{\mathrm{d}} f_{e, l} \sigma_{\mathrm{e}}=n_{0} e^{-E_{\mathrm{f}}^{\min } / k_{\mathrm{B}} T}\left(1-\frac{1}{1+e^{\left(E_{1}-E_{\mathrm{F}}\right) / k_{\mathrm{B}} T}}\right) \sigma_{\mathrm{e}} \\
& r_{h-\text { trap }}=c_{\mathrm{d}} f_{h, l} \sigma_{\mathrm{h}}=n_{0} e^{-E_{\mathrm{f}}^{\min } / k_{\mathrm{B}} T} \frac{1}{1+e^{\left(E_{1}-E_{\mathrm{F}}\right) / k_{\mathrm{B}} T}} \sigma_{\mathrm{h}} .
\end{aligned}
$$

Here $c_{\mathrm{d}}=n_{0} e^{-E_{\mathrm{f}}^{\min } / k_{\mathrm{B}} T}, n_{0}$ is the possible sites for the defect and $E_{\mathrm{l}}$ is the position of the defect energy level. Previous studies have found that the Coulomb interaction between the carriers and defects has a critical role: the typical capture cross-sections of repulsive centers, neutral centers and attractive centers are $10^{-8}-10^{-5}, 10^{-1}-10^{1}$ and $10^{1}-10^{4} \AA^{2}$, respectively. ${ }^{45}$ We approximate $\sigma_{\mathrm{e}}$ and $\sigma_{\mathrm{h}}$ as the intermediate values of the abovementioned ranges, as written in Equation (5).

$$
\sigma_{\mathrm{e}}=\left\{\begin{array}{l}
5 \times 10^{3}, q>0 \\
5, q=0 \\
5 \times 10^{-6}, q<0
\end{array}, \sigma_{\mathrm{h}}=\left\{\begin{array}{l}
5 \times 10^{3}, q<0 \\
5, q=0 \\
5 \times 10^{-6}, q>0
\end{array}\right.\right.
$$

where $q$ is the charge state of the defect. Tests show that the exponential prefactor dominates Equation (4), and even two orders of uncertainty of $\sigma_{\mathrm{e}}$ and $\sigma_{\mathrm{h}}$ results in minor changes to Figure 3.

Figure 3 shows that the minority-electron traps are dominated by $\mathrm{As}_{\mathrm{Ga}}, \mathrm{Bi}_{\mathrm{Ga}}, \mathrm{As}_{\mathrm{Ga}}+\mathrm{Bi}_{\mathrm{As}}$ and $\mathrm{Bi}_{\mathrm{Ga}}+\mathrm{Bi}_{\mathrm{As}}$ under p-type doping conditions and the minority-hole traps are dominated by $V_{\mathrm{Ga}}$ and $V_{\mathrm{Ga}}+\mathrm{Bi}_{\mathrm{As}}$ under $n$-type doping conditions. Note that, because $\mathrm{Bi}_{\mathrm{Ga}}+\mathrm{Bi}_{\mathrm{As}}$ is expected to have a significant concentration under non-equilibrium conditions (Supplementary Figure S4) despite its high defect formation energy, we reduce $E_{\mathrm{f}}^{\mathrm{min}}$ by $0.43 \mathrm{eV}$ per $\mathrm{Bi}$ atom for all $\mathrm{Bi}$ defects (an amplitude corresponding to half of the $\mu_{\mathrm{Bi}}$ decrease at the

Table 3 Comparison between previous experiments ${ }^{43}$ and this work for primary majority-electron traps in n-type GaAsBi films and majority-hole traps in p-type ones

This work

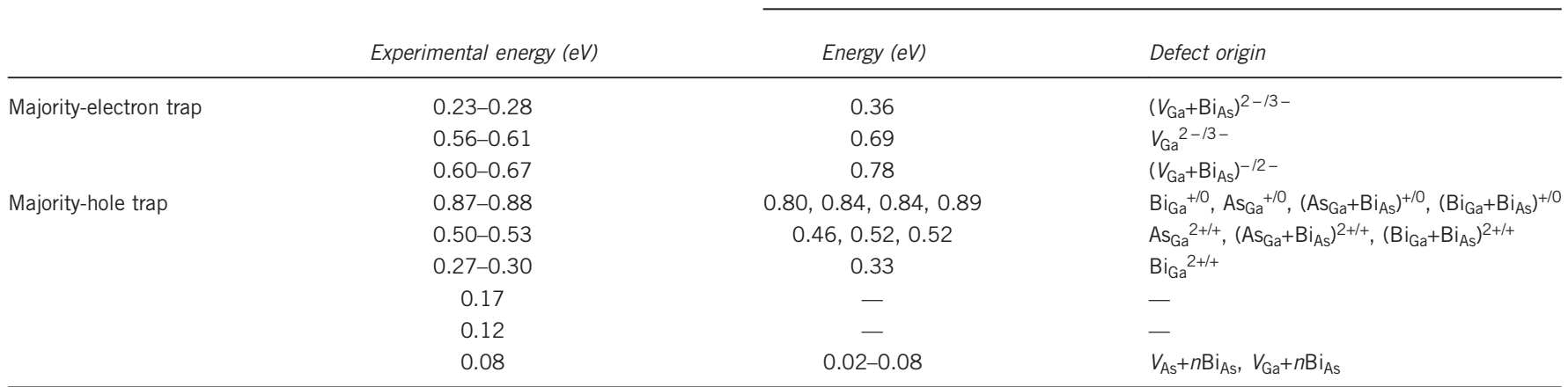

Energy levels of majority-electron traps are relative values below conduction band minimum and majority-holes traps above VBM. Defect origins predicted by this work are listed for corresponding energy levels. 


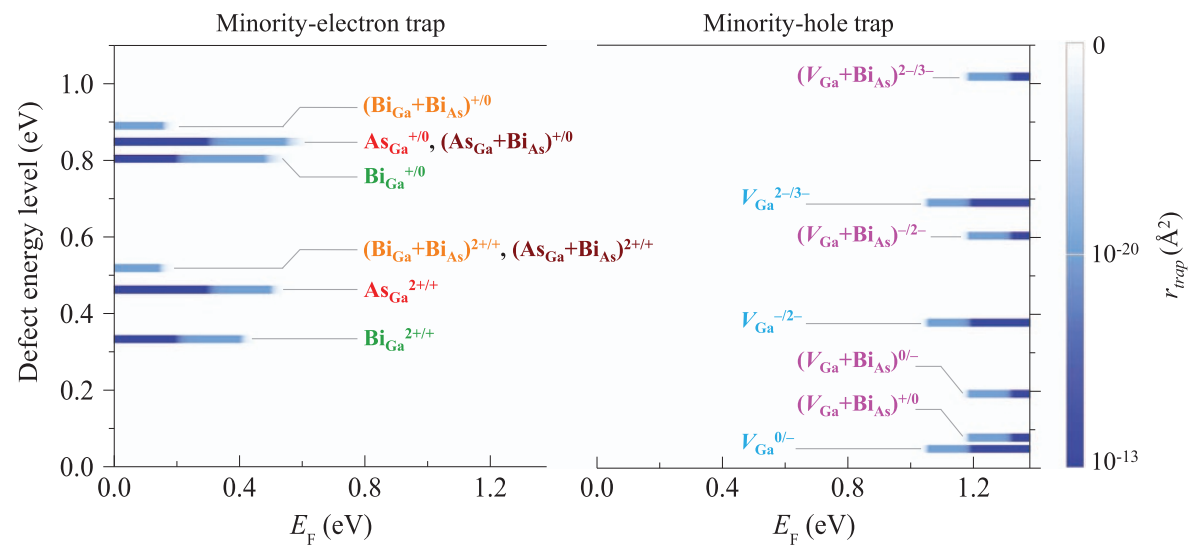

Figure 3 Trapping rate as a function of Fermi energy for (left) minority-electron and (right) minority-hole traps induced by the energy levels of all examined point and pair defects. Energy levels with an extremely low trapping rate are invisible within the color-mapping scheme. Temperature is set to $300 \mathrm{~K}$.
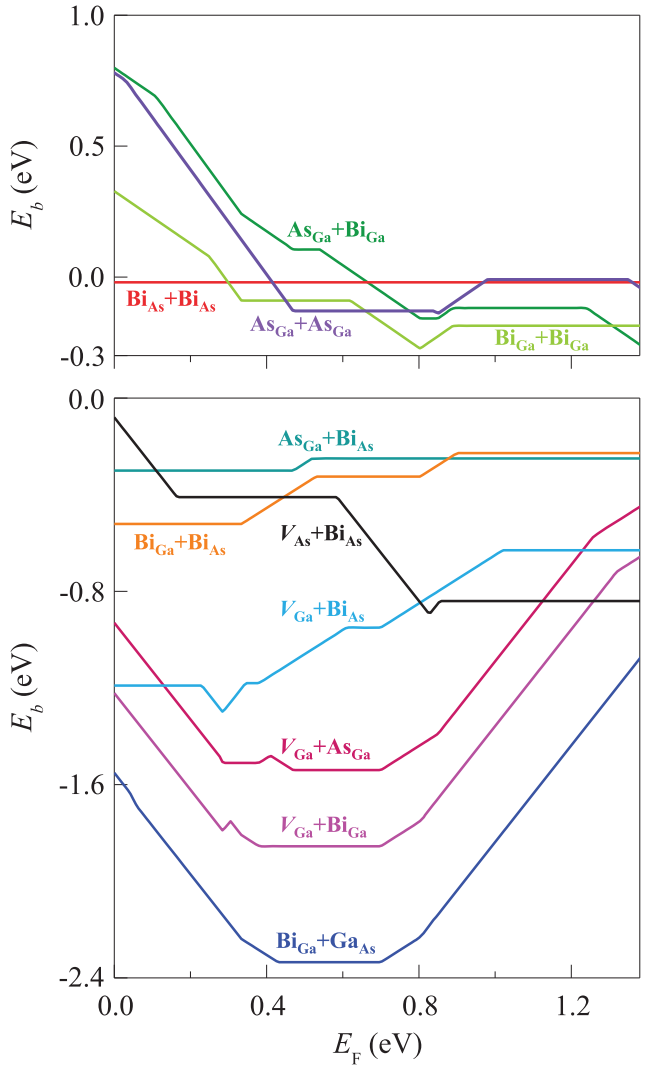

Figure 4 Binding energy of pair defects relative to isolated point defects. The plots are shown in two panels for easy visualization.

$\mathrm{VBM}$ in the aforementioned non-equilibrium estimation) to include $\mathrm{Bi}_{\mathrm{Ga}}+\mathrm{Bi}_{\mathrm{As}}$ in Figure 3. A similar figure without this correction can be found in Supplementary Figure S5. As all the primary traps contain at least one of the unwanted point defects, $\mathrm{As}_{\mathrm{Ga}}, \mathrm{Bi}_{\mathrm{Ga}}$ and $V_{\mathrm{Ga}}$, one should be able to effectively minimize the traps by an efficient reduction of the three point defects.

Binding energy of pair defects and formation of Bi-rich clusters To determine how point defects interact and form pair defects (important processes during thermal annealing), we plot the binding energy of pair defects (Figure 4). We find that $\mathrm{Bi}_{\mathrm{As}}+\mathrm{Bi}_{\mathrm{As}}$ has slightly negative $(-0.02 \mathrm{eV})$ binding energies in the entire range of Fermi energy. $\mathrm{Bi}_{\mathrm{Ga}}+\mathrm{Bi}_{\mathrm{Ga}}, \mathrm{As}_{\mathrm{Ga}}+\mathrm{As}_{\mathrm{Ga}}$ and $\mathrm{As}_{\mathrm{Ga}}+\mathrm{Bi}_{\mathrm{Ga}}$ have positive binding energies when $E_{\mathrm{F}}$ is less than $0.29,0.40$ and $0.65 \mathrm{eV}$, respectively, and slightly negative binding energies otherwise. In view of their relatively high formation energies (Figure 1c), the three pair defects are expected to form in a small quantity over a limited range of Fermi energy. By contrast, all the other pair defects, including those with high contents under equilibrium or non-equilibrium conditions $\left(\mathrm{As}_{\mathrm{Ga}}+\mathrm{Bi}_{\mathrm{As}}, \mathrm{Bi} \mathrm{i}_{\mathrm{Ga}}\right.$ $+\mathrm{Bi}_{\mathrm{As}}$ and $V_{\mathrm{Ga}}+\mathrm{Bi}_{\mathrm{As}}$ ), possess negative binding energies in the entire range of Fermi energy. The pair defects involving $\mathrm{Bi}$ and vacancies have particularly low binding energies; thus the Bi-vacancy pairs likely provide the nuclei of the Bi-rich clusters during thermal annealing. Although $\mathrm{Bi}_{\mathrm{Ga}}+\mathrm{Ga}_{\mathrm{As}}$ also has low binding energy, its overall formation energy is $>3.1 \mathrm{eV}$ (Figure 1c), which means that its content should be low, even in the presence of a significant $\mathrm{Bi}$ content under non-equilibrium conditions (Supplementary Figure S4).

To further examine whether a vacancy can bind multiple Bi defects together, we study relatively large clusters with and without a vacancy in the cluster center, namely, $n \mathrm{Bi}_{\mathrm{As}}, n \mathrm{Bi}_{\mathrm{Ga}}, V_{\mathrm{Ga}}+n \mathrm{Bi}_{\mathrm{As}}$ and $V_{\mathrm{As}}+n \mathrm{Bi}_{\mathrm{As}}$ $(n=3$ and 4$)$. It turns out that pure $\mathrm{Bi}$ clusters have repulsive interactions in most regions of $E_{\mathrm{F}}$, but a vacancy strongly binds the $\mathrm{Bi}$ defects together (Supplementary Figure S6). Such behavior can be partially attributed to the compensation of the strain induced by $\mathrm{Bi}$ defects and vacancies. Our results support and extend the conclusion of a previous density functional theory study, ${ }^{46}$ which reported the nucleus effect of $V_{\mathrm{Ga}}{ }^{0}$ in the formation of Bi-rich clusters using the LDA functional. In addition to the strong binding strength, the formation of Bi-rich clusters with vacancies rather than pure $\mathrm{Bi}$ clusters is supported by another fact: $V_{\mathrm{As}}+3 \mathrm{Bi}_{\mathrm{As}}, V_{\mathrm{As}}+4 \mathrm{Bi}_{\mathrm{As}}$ and $V_{\mathrm{Ga}}+4 \mathrm{Bi}_{\mathrm{As}}$ possess energy levels $0.02-0.08 \mathrm{eV}$ above the VBM (Supplementary Figures S6a and b), which agrees with previous experimental observations of Bi-included localized states 0.05- $0.09 \mathrm{eV}$ above the VBM. ${ }^{47}$ By contrast, all the examined pure $\mathrm{Bi}$ defects $\left(m \mathrm{Bi}_{\mathrm{As}}\right.$ for $m=1-4$ and $n \mathrm{Bi}_{\mathrm{Ga}}$ for $\left.n=1-2\right)$ do not have similar energy levels.

In addition to serving as nuclei of the Bi-rich clusters, vacancies are expected to have a critical role in assisting the diffusion of Bi during the cluster formation, as the very large size of $\mathrm{Bi}$ atoms relative to $\mathrm{Ga}$ and As atoms makes it unlikely to be an interstitial diffuser. Unfortunately, the complete and quantitative modeling of the defect-mediated Bi diffusion over all possible Fermi levels and external chemical potentials is complex and beyond the scope of this paper. We therefore focus on building a simplified model under As-rich and 
a

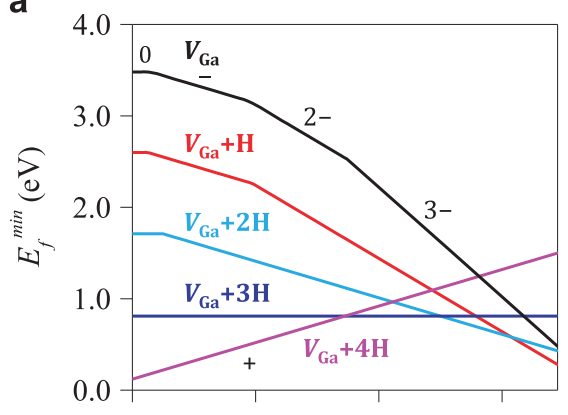

C

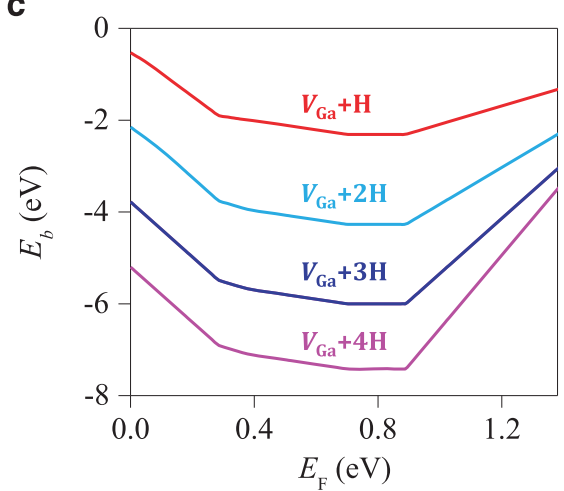

b

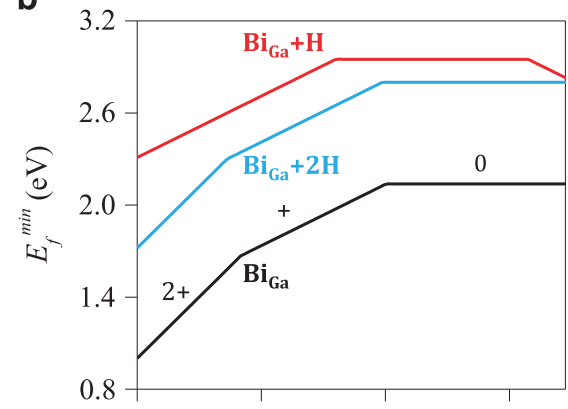

d

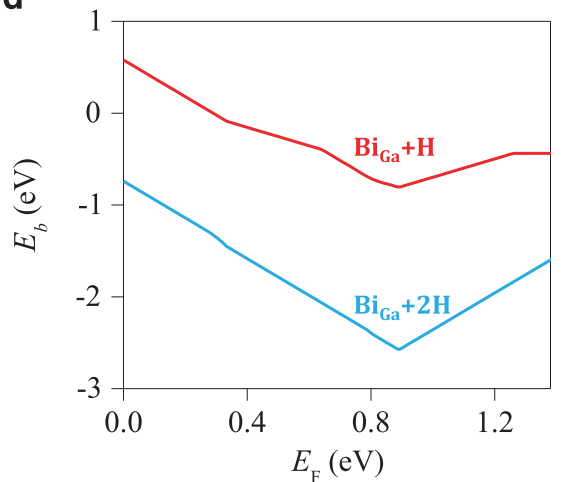

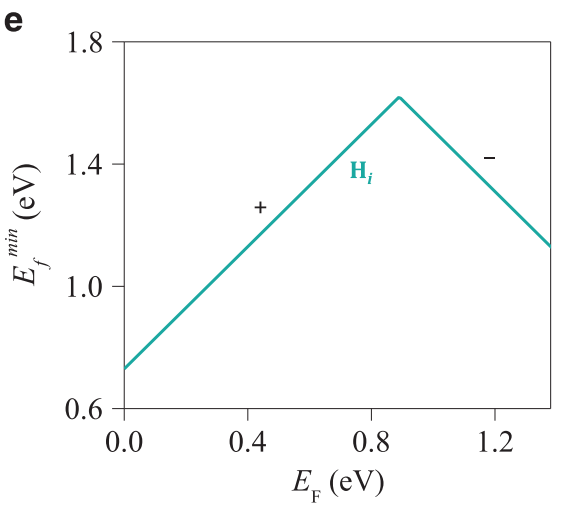

Figure 5 Lowest defect formation energy of (a) $V_{\mathrm{Ga}}+n \mathrm{H}$ and (b) $\mathrm{Bi}_{\mathrm{Ga}}+n \mathrm{H}$ and binding energies of (c) $V_{\mathrm{Ga}}+n \mathrm{H}$ and (d) $\mathrm{Bi}_{\mathrm{Ga}}+n \mathrm{H}$. (e) Lowest defect formation energy of $\mathrm{H}_{\mathrm{i}}$. The binding energy is relative to isolated $\mathrm{H}_{\mathrm{i}}$ and $V_{\mathrm{Ga}}$ or $\mathrm{Bi}_{\mathrm{Ga}}$. The chemical potential of $\mathrm{H}$ is selected as half of the energy of a $\mathrm{H}_{2}$ molecule (other choices of the chemical potential only shift the curve in (e) up or down). Several structures of $V_{\mathrm{Ga}}+n \mathrm{H}, \mathrm{Bi}_{\mathrm{Ga}}+n \mathrm{H}$ and $\mathrm{H}_{\mathrm{i}}$ can be found in Supplementary Figure S9.

$n$-type doping conditions. If we make a reasonable assumption that $\mathrm{Bi}$ diffuses by a vacancy-mediated mechanism with nearest-neighbor hops on either the $\mathrm{Ga}$ or As sublattice, then the diffusions must involve the formation of the pair defect $V_{\mathrm{Ga}}+\mathrm{Bi}_{\mathrm{Ga}}$ or $V_{\mathrm{As}}+\mathrm{Bi}_{\mathrm{As}}$. Because $V_{\mathrm{Ga}}+\mathrm{Bi}_{\mathrm{Ga}}$ is significantly more stable than $V_{\mathrm{As}}+\mathrm{Bi}_{\mathrm{As}}$ for all Fermi levels (Figure 1b) and has a significantly stronger binding strength than $V_{\mathrm{As}}+\mathrm{Bi}_{\mathrm{As}}$ for almost all Fermi levels (Figure 4), it is likely that the primary $\mathrm{Bi}$ diffusion path is through the $V_{\mathrm{Ga}}$-mediated diffusion of $\mathrm{Bi}_{\mathrm{Ga}}$. Additionally, Figure $1 \mathrm{~b}$ shows that $V_{\mathrm{Ga}}+\mathrm{Bi}_{\mathrm{Ga}}$ is stable in the 1 - charge state over a wide range of Fermi energy. Therefore, we focus on $\mathrm{Bi}_{\mathrm{Ga}}$ diffusion through $V_{\mathrm{Ga}}$-mediated hops, with the whole system in the 1 - charge state; the diffusion of isolated $V_{\mathrm{Ga}}$ is assumed to be in the dominant 3- charge state.

We calculate the $V_{\mathrm{Ga}}$-mediated $\mathrm{Bi}_{\mathrm{Ga}}$ diffusion using the well-known five-frequency model, as elaborated in Supplementary Information VIII. Six critical parameters for the model, namely, the migration barriers of processes $0-4$ and the self-diffusivity of $\mathrm{Ga}$, are found to be $2.16 \mathrm{eV}, 2.47 \mathrm{eV}, 1.79 \mathrm{eV}, 2.54 \mathrm{eV}, 1.98 \mathrm{eV}$ and $4.3 \times 10^{17} e^{\left(6.78 \mathrm{eV}-3 E_{\mathrm{F}}\right) /\left(k_{\mathrm{B}} T\right)} \AA^{2} \mathrm{~s}^{-1}$, respectively. We observe that, in the typical annealing temperature range of $600-800^{\circ} \mathrm{C}$ and annealing time range of $60-120 \mathrm{~s}$, the diffusion length of $\mathrm{Bi}_{\mathrm{Ga}}$ is sufficiently long to promote the formation of Bi-rich clusters under the n-type doping condition. For example, a 60 -s annealing at $800^{\circ} \mathrm{C}$ leads to a $\mathrm{Bi}_{\mathrm{Ga}}$ diffusion length over $20 \AA$ for $E_{\mathrm{F}}>0.91 \mathrm{eV}$. By contrast, for a GaAsBi film with $1.0-3.0 \%$ uniformly distributed $\mathrm{Bi}$ atoms, the average distance between two neighboring $\mathrm{Bi}$ atoms is only approximately 16-11 $\AA$. Therefore, $V_{\mathrm{Ga}}$ is capable of assisting $\mathrm{Bi}_{\mathrm{Ga}}$ diffusion to form Bi-rich clusters in typical GaAsBi films, with typical annealing temperatures and time. This mechanism of $\mathrm{Bi}$ clustering is also supported by the fact that $V_{\mathrm{Ga}}$ assists the diffusion of $\mathrm{As}_{\mathrm{Ga}}$ to form
As-rich clusters during the thermal annealing of low temperaturegrown GaAs. ${ }^{48,49}$ Because of the strong binding between $V_{\mathrm{Ga}}$ and $\mathrm{Bi}_{\mathrm{Ga}}$ as well as the relatively fast $V_{\mathrm{Ga}}$-mediated $\mathrm{Bi}_{\mathrm{Ga}}$ diffusion, we anticipate that the initial Bi-rich clusters consist of both $\mathrm{Bi}$ and $V_{\mathrm{Ga}}$ and that minimizing the content of $V_{\mathrm{Ga}}$ is expected to effectively reduce the formation of Bi-rich clusters under thermal annealing.

\section{Hydrogen passivation of defects}

To explore the methods of reducing the deleterious influence of defects, we first examine the hydrogen passivation of the dominant defects, a technology that is widely used in the silicon industry to reduce carrier traps. Figure $5 \mathrm{a}$ shows that hydrogen can effectively passivate $V_{\mathrm{Ga}}$ : the number of deep energy levels of $V_{\mathrm{Ga}}+n \mathrm{H}$ is reduced from three to zero as the number of hydrogen atoms, $n$, increases from zero to three. Interestingly, adding a fourth hydrogen atom around $V_{\mathrm{Ga}}$ does not induce an extra defect energy level in the gap, which therefore allows a relatively wide range of hydrogen passivation conditions without the creation of new gap states. Thermodynamically, the $\mathrm{H}$-passivated $V_{\mathrm{Ga}}$ are much more stable (over $0.53 \mathrm{eV}$ per $V_{\mathrm{Ga}}$ ) compared with the isolated $V_{\mathrm{Ga}}$ and hydrogen interstitial $\mathrm{H}_{\mathrm{i}}$, as shown in Figure $5 c$. Note that $\mathrm{H}_{\mathrm{i}}$ is known to be able to exist in bulk GaAs under common metalorganic vapor-phase epitaxy conditions. ${ }^{50}$ Therefore, hydrogen passivation is likely to be realized, and it could effectively remove the defect levels induced by $V_{\mathrm{Ga}}$. An additional advantage is that $V_{\mathrm{Ga}}$ is expected to diffuse significantly slower after passivation, which will reduce $\mathrm{Bi}_{\mathrm{Ga}}$ diffusion and, consequently, the formation of Bi-rich clusters. Because of the similarity between $V_{\mathrm{Ga}}$ and $V_{\mathrm{Ga}}+\mathrm{Bi}_{\mathrm{As}}$, it is likely that hydrogen passivation can also effectively remove the defect energy levels of $V_{\mathrm{Ga}}+\mathrm{Bi}_{\mathrm{As}}$. 
a

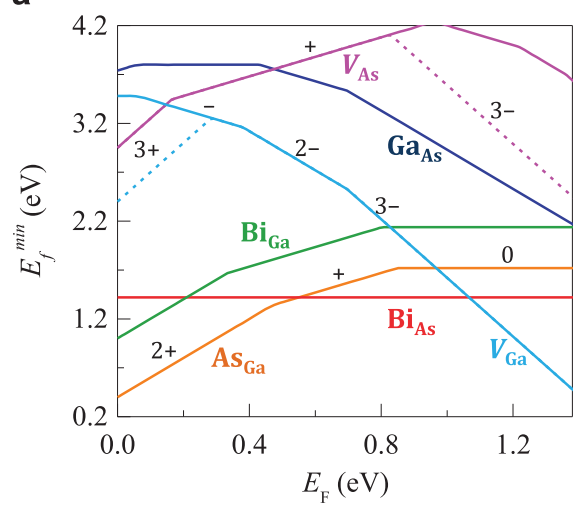

b

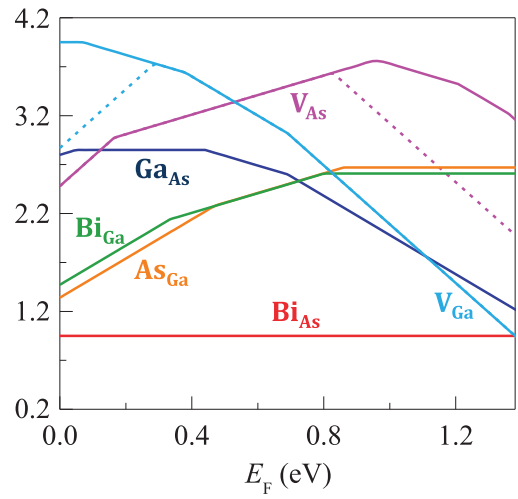

C

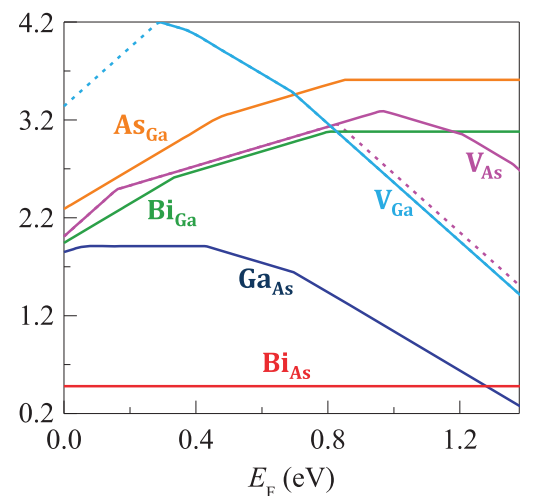

Figure 6 Lowest defect formation energy of point defects under the (a) As-rich, (b) intermediate and (c) Ga-rich conditions. The magenta and blue dashed branches correspond to the swapped structures of $V_{\mathrm{Ga}}$ and $V_{\mathrm{As}}$, respectively, as presented in Table 2.

In contrast to $V_{\mathrm{Ga}}$, hydrogen passivation does not remove the deep defect levels of $\mathrm{Bi}_{\mathrm{Ga}}$ : both $\mathrm{Bi}_{\mathrm{Ga}}+\mathrm{H}$ and $\mathrm{Bi}_{\mathrm{Ga}}+2 \mathrm{H}$ have two deep defect levels in the band gap, as is $\mathrm{Bi}_{\mathrm{Ga}}$ (Figure $5 \mathrm{~b}$ ). The binding energy of $\mathrm{Bi}_{\mathrm{Ga}}+\mathrm{H}$ is positive at $E_{\mathrm{F}}<0.29 \mathrm{eV}$ (Figure $5 \mathrm{~d}$ ), indicating that $\mathrm{H}$ passivation cannot even be realized under such condition. For $\mathrm{Bi}_{\mathrm{Ga}}$ $+2 \mathrm{H}$, the two hydrogen atoms form a $\mathrm{H}_{2}$ molecule (Supplementary Figure S9) rather than bind to $\mathrm{Bi}_{\mathrm{Ga}}$, and the shape of its defect formation energy curve resembles that of $\mathrm{Bi}_{\mathrm{Ga}}$ (Figure $5 \mathrm{~b}$ ).

Nevertheless, it is anticipated that hydrogenation would reduce the presence of defect $\mathrm{Bi}_{\mathrm{Ga}}$ by shifting up $E_{\mathrm{F}}$. Figure 1a shows that $\mathrm{Bi}_{\mathrm{Ga}}$ exists primarily under p-type conditions, and its formation energy increases with $E_{\mathrm{F}}$ until $0.81 \mathrm{eV}$, where $\mathrm{H}_{\mathrm{i}}$ is a donor (Figure $5 \mathrm{e}$ ). Therefore, $\mathrm{H}_{\mathrm{i}}$ will increase $E_{\mathrm{F}}$ and exponentially decrease the equilibrium content of $\mathrm{Bi}_{\mathrm{Ga}}$ for $E_{\mathrm{F}}<0.81 \mathrm{eV}$. Consistent with this prediction, previous experiments clearly showed that hydrogenation reduced the deep-level transient spectroscopic signal of $\mathrm{As}_{\mathrm{Ga}}$ in GaAs. ${ }^{51}$ Because of the similarity between $\mathrm{Bi}_{\mathrm{Ga}}$ and the three other primary defects, namely, $\mathrm{As}_{\mathrm{Ga}}, \mathrm{As}_{\mathrm{Ga}}+\mathrm{Bi}_{\mathrm{As}}$ and $\mathrm{Bi}_{\mathrm{Ga}}+\mathrm{Bi}_{\mathrm{As}}$, it is likely that hydrogenation would have similar effects on them.

However, because $\mathrm{H}_{\mathrm{i}}$ introduces a defect level at $0.89 \mathrm{eV}$ (Figure 5e), which would negatively impact device performance, it is necessary to gradually increase the hydrogenation to identify the conditions that lead to the best device performance. Consistent with this observation, previous experiments determined that moderate hydrogenation prominently increased the photoluminescence intensity of GaAs, but high hydrogen doses worsened it. ${ }^{52}$

\section{Influence of external chemical potentials}

Another method to potentially reduce the unwanted defects is by manipulating the external chemical potentials of $\mathrm{Ga}$, As and $\mathrm{Bi}$, which do not affect the positions of the defect energy levels but strongly influence the defect formation energies. Figures $6 a-c$ show the formation energies of the point defects under As-rich, intermediate and Ga-rich conditions, respectively. The formation energies of defects involving the As site, namely, $V_{\mathrm{As}}, \mathrm{Ga}_{\mathrm{As}}$ and $\mathrm{Bi}_{\mathrm{As}}$, dramatically decrease when the chemical potential changes from more As-rich to more Ga-rich conditions, whereas the defects involving the Ga-site, namely $V_{\mathrm{Ga}}, \mathrm{As}_{\mathrm{Ga}}$ and $\mathrm{Bi}_{\mathrm{Ga}}$, sharply increase accordingly. Indeed, previous experiments found that the $V_{\mathrm{Ga}}$ content increases with the As vapor pressure. ${ }^{33}$ Among the three conditions, the intermediate and Ga-rich conditions generate the fewest unwanted defects for the n- and p-type films, respectively. By contrast, the usual As-rich condition generates a significant number of unwanted defects for both types of doping.
To avoid the As-rich growth condition, we suggest a more precise introduction of the As reactant, for example, using a pulsed As beam/precursor rather than filling the entire growth chamber with excessive As reactant, a method having also been proposed to increase the $\mathrm{Bi}$ ratio in GaAsBi. ${ }^{12}$ Additionally, one might explore the pulsed laser deposition method, ${ }^{53}$ which uses the plasma produced from bulk GaAs as the reactant and thus creates chemical potentials close to the intermediate condition.

\section{Summary}

In summary, we investigate the defect thermodynamics and $\mathrm{Bi}$ segregation in GaAsBi using density functional theory. We obtain defect energy levels that correspond reasonably well to the measured levels in GaAs and GaAsBi alloys and provide valuable insight into the nature of previously observed defect energy levels in GaAsBi. We find that a cation (anion) vacancy can change to an anion (cation) vacancy at certain charge states, and this phenomenon exists in a number of semiconductors with low ionicity. Under the usual As-rich growth condition, $\mathrm{As}_{\mathrm{Ga}}, \mathrm{Bi}_{\mathrm{Ga}}, \mathrm{As}_{\mathrm{Ga}}+\mathrm{Bi}_{\mathrm{As}}$ and $\mathrm{Bi}_{\mathrm{Ga}}+\mathrm{Bi}_{\mathrm{As}}$ are the major minorityelectron traps in p-type films, whereas $V_{\mathrm{Ga}}$ and $V_{\mathrm{Ga}}+\mathrm{Bi}_{\mathrm{As}}$ are the major minority-hole traps in n-type films. We predict that $V_{\mathrm{Ga}}$ serves as the nuclei of the Bi-rich clusters and assists the diffusion of Bi defects. To reduce the deleterious effects of defects, we propose using hydrogen passivation to decrease the minority-carrier traps and/or changing the growth to the Ga-rich or intermediate chemical potential conditions.

\section{CONFLICT OF INTEREST}

The authors declare no conflict of interest.

\section{ACKNOWLEDGEMENTS}

This research was primarily supported by the NSF through the University of Wisconsin Materials Research Science and Engineering Center (Grant No DMR-1121288). Glen R Jenness and Zhewen Song were supported by the NSF Software Infrastructure for Sustained Innovation (SI2) award No 1148011.

The authors gratefully acknowledge the use of computer clusters supported by the NSF through the University of Wisconsin Materials Research Science and Engineering Center (Grant No DMR-1121288). Computations in this work also benefited from the use of the Extreme Science and Engineering Discovery Environment (XSEDE), which is supported by the National Science Foundation Grant No ACI-1053575, the computing resources and assistance of the UW-Madison Center For High Throughput Computing (CHTC) in the Department of Computer Sciences and the National Energy Research Scientific Computing Center (NERSC), a DOE Office of Science User Facility supported by the Office of Science of the US Department of Energy under Contract No DE-AC02-05CH11231. 
1 Oe, K. \& Okamoto, H. New semiconductor alloy $\mathrm{GaAs}_{1-x} \mathrm{Bi}_{x}$ grown by metal organic vapor phase epitaxy. Jpn J. Appl. Phys. 37, L1283 (1998).

2 Tixier, S., Adamcyk, M., Tiedje, T., Francoeur, S., Mascarenhas, A., Wei, P. \& Schiettekatte, F. Molecular beam epitaxy growth of $\mathrm{GaAs}_{1-x} \mathrm{Bi}$. Appl. Phys. Lett. 82, 2245 (2003).

3 Li, H. \& Wang, Z. M. Bismuth-Containing Compounds (Springer: New York, USA, 2013).

4 Yoshida, J., Kita, T., Wada, O. \& Oe, K. Temperature dependence of $\mathrm{GaAs}_{1-x} \mathrm{Bi}_{x}$ band gap studied by photoreflectance spectroscopy. Jpn. J. Appl. Phys. 42, 371 (2003)

5 Broderick, C. A., Usman, M., Sweeney, S. J. \& O'Reilly, E. P. Band engineering in dilute nitride and bismide semiconductor lasers. Semicond. Sci. Technol. 27, 094011 (2012).

6 Fuyuki, T., Yoshida, K., Yoshioka, R. \& Yoshimoto, M. Electrically pumped roomtemperature operation of $\mathrm{GaAs}_{1-x} \mathrm{Bi}_{x}$ laser diodes with low-temperature dependence of oscillation wavelength. Appl. Phys. Express 7, 082101 (2014).

7 Beyer, A., Stolz, W. \& Volz, K. Metastable cubic zinc-blende III/V semiconductors: growth and structural characteristics. Prog. Cryst. Growth Charact. Mater. 61, 46 (2015).

8 Richards, R. D., Bastiman, F., Hunter, C. J., Mendes, D. F., Mohmad, A. R., Roberts, J. S. \& David, J. P. R. Molecular beam epitaxy growth of GaAsBi using $\mathrm{As}_{2}$ and As4. J. Cryst. Growth 390, 120 (2014).

9 Jacobsen, H., Puchala, B., Kuech, T. F. \& Morgan, D. Ab initio study of the strain dependent thermodynamics of Bi doping in GaAs. Phys. Rev. B 86, 085207 (2012).

10 Pacebutas, V., Bertulis, K., Aleksejenko, G. \& Krotkus, A. Molecular-beam-epitaxy grown GaBiAs for terahertz optoelectronic applications. J. Mater. Sci. Mater. Electron. 20, 363 (2009).

11 Pačebutas, V., Butkutè, R., Čechavičius, B., Kavaliauskas, J. \& Krotkus, A. Photoluminescence investigation of $\mathrm{GaAs}_{1-\chi} \mathrm{Bi}_{x} / \mathrm{G}$ aAs heterostructures. Thin Solid Films 520, 6415 (2012).

12 Luo, G. F., Yang, S. J., Li, J. C., Arjmand, M., Szlufarska, I., Brown, A. S., Kuech, T. F. \& Morgan, D. First-principles studies on molecular beam epitaxy growth of $\mathrm{GaAs}_{1-x} \mathrm{Bi}_{x}$. Phys. Rev. B 92, 035415 (2015).

13 Wu, M. J., Luna, E., Puustinen, J., Guina, M. \& Trampert, A. Formation and phase transformation of Bi-containing QD-like clusters in annealed GaAsBi. Nanotechnology 25, 205605 (2014).

14 Marko, I. P., Ludewig, P., Bushell, Z. L., Jin, S. R., Hild, K., Batool, Z., Reinhard, S. Nattermann, L., Stolz, W., Volz, K. \& Sweeney, S. J. Physical properties and optimization of $\mathrm{GaBiAs} /(\mathrm{Al}) \mathrm{GaAs}$ based near-infrared laser diodes grown by MOVPE with up to 4.4\% Bi. J. Phys. D Appl. Phys 47, 345103 (2014).

15 Marko, I. P., Jin, S. R., Hild, K., Batool, Z., Bushell, Z. L., Ludewig, P., Stolz, W., Volz, K., Butkute, R., Pacebutas, V., Geizutis, A., Krotkus, A. \& Sweeney, S. J. Properties of hybrid MOVPE/MBE grown GaAsBi/GaAs based near-infrared emitting quantum well lasers. Semicond. Sci. Technol. 30, 094008 (2015).

16 Marko, I. P., Broderick, C. A., Jin, S. R., Ludewig, P., Stolz, W., Volz, K., Rorison, J. M., O'Reilly, E. P. \& Sweeney, S. J. Optical gain in GaAsBi/GaAs quantum well diode lasers. Sci. Rep. 6, 28863 (2016).

17 Schick, J. T. \& Morgan, C. G. Gallium interstitial contributions to diffusion in gallium arsenide. AIP Adv. 1, 032161 (2011).

18 Schick, J. T., Morgan, C. G. \& Papoulias, P. First-principles study of As interstitials in GaAs: convergence, relaxation, and formation energy. Phys. Rev. B 66, 195302 (2002).

19 Kresse, G. \& Furthmuller, J. Efficient iterative schemes for ab initio total-energy calculations using a plane-wave basis set. Phys. Rev. B 54, 11169 (1996).

20 Heyd, J., Scuseria, G. E. \& Ernzerhof, M. Hybrid functionals based on a screened Coulomb potential. J. Chem. Phys. 118, 8207 (2003).

21 Blakemore, J. S. Semiconducting and other major properties of gallium arsenide. J. Appl. Phys. 53, R123 (1982).

22 Freysoldt, C., Neugebauer, J. \& Van de Walle, C. G. Fully ab initio finite-size corrections for charged-defect supercell calculations. Phys. Rev. Lett. 102, 016402 (2009).

23 Angsten, T., Mayeshiba, T., Wu, H. \& Morgan, D. Elemental vacancy diffusion database from high-throughput first-principles calculations for fcc and hcp structures. New J. Phys. 16, 015018 (2014).

24 Freysoldt, C., Grabowski, B., Hickel, T., Neugebauer, J., Kresse, G., Janotti, A. \& Van de Walle, C. G. First-principles calculations for point defects in solids. Rev. Mod. Phys. 86, 253 (2014).

25 Yamaguchi, K., Takeda, Y., Kameda, K. \& Itagaki, K. Measurements of heat of formation of GaP, InP, GaAs, InAs, GaSb and InSb. Mater. Trans. JIM 35, 596 (1994).

26 Baraff, G. A. \& Schluter, M. Bistability and metastability of the gallium vacancy in GaAs: the actuator of EL2. Phys. Rev. Lett. 55, 2340 (1985).

27 Baraff, G. A. \& Schluter, M. Binding and formation energies of native defect pairs in GaAs. Phys. Rev. B 33, 7346 (1986)

28 El-Mellouhi, F. \& Mousseau, N. Self-vacancies in gallium arsenide: an ab initio calculation. Phys. Rev. B 71, 125207 (2005).

29 Komsa, H.-P. \& Pasquarello, A. Intrinsic defects in GaAs and InGaAs through hybrid functional calculations. Phys. B 407, 2833 (2012).

30 Wosinski, T., Makosa, A. \& Witczak, Z. Transformation of native defects in bulk GaAs under ultrasonic vibration. Semicond. Sci. Technol. 9, 2047 (1994).
31 Kunzer, M., Jost, W., Kaufmann, U., Hobgood, H. M. \& Thomas, R. N. Identification of the $\mathrm{Bi}_{\mathrm{Ga}}$ heteroantisite defect in GaAs:Bi. Phys. Rev. B 48, 4437 (1993).

32 Ciatto, G., Alippi, P., Bonapasta, A. A. \& Tiedje, T. How much room for $\mathrm{Bi}_{\mathrm{Ga}}$ heteroantisites in $\mathrm{GaAs}_{1-x} \mathrm{Bi}_{x}$ ? Appl. Phys. Lett. 99, 141912 (2011).

33 Gebauer, J., Lausmann, M., Redmann, F., Krause-Rehberg, R., Leipner, H. S., Weber, E. R. \& Ebert, P. Determination of the Gibbs free energy of formation of Ga vacancies in GaAs by positron annihilation. Phys. Rev. B 67, 235207 (2003).

34 Milnes, A. G. Impurity and defect levels (experimental) in gallium arsenide. Adv. Electron. Electron Phys 61, 63 (1983).

35 Saarinen, K., Hautojarvi, P., Lanki, P. \& Corbel, C. Ionization levels of As vacancies in as-grown GaAs studied by positron-lifetime spectroscopy. Phys. Rev. B 44, 10585 (1991).

36 Loualiche, S., Nouailhat, A., Guillot, G. \& Lannoo, M. Interpretation of deep-level optical spectroscopy and deep-level transient spectroscopy data: application to irradiation defects in GaAs. Phys. Rev. B 30, 5822 (1984).

37 Lagowski, J., Lin, D. G., Chen, T. P., Skowronski, M. \& Gatos, H. C. Native hole trap in bulk GaAs and its association with the double-charge state of the arsenic antisite defect. Appl. Phys. Lett. 47, 929 (1985)

38 Weber, E. R., Ennen, H., Kaufmann, U., Windscheif, J., Schneider, J. \& Wosinski, T. Identification of $\mathrm{As}_{\mathrm{Ga}}$ antisites in plastically deformed GaAs. J. Appl. Phys. 53, 6140 (1982).

39 Fuyuki, T., Kashiyama, S., Tominaga, Y., Oe, K. \& Yoshimoto, M. Deep-hole traps in p-type $\mathrm{GaAs}_{1-x} \mathrm{Bi}_{x}$ grown by molecular beam epitaxy. Jpn J. Appl. Phys. 50, 080203 (2011)

40 Wang, Z. G., Ledebo, L. A. \& Grimmeiss, H. G. Electronic-properties of native deep-level defects in liquid-phase epitaxial GaAs. J. Phys. Condes. Matter 17, 259 (1984).

41 Elliott, K. R., Holmes, D. E., Chen, R. T. \& Kirkpatrick, C. G. Infrared absorption of the 78-meV acceptor in GaAs. Appl. Phys. Lett. 40, 898 (1982).

42 Mihara, M., Mannoh, M., Shinozaki, K., Naritsuka, S. \& Ishii, M. Photoluminescence of the $78 \mathrm{meV}$ acceptor in GaAs layers grown by molecular beam epitaxy. Jpn. J. Appl. Phys. 25, L611 (1986).

43 Mooney, P. M., Tarun, M., Beaton, D. A., Mascarenhas, A. \& Alberi, K. Deep level defects in dilute GaAsBi alloys grown under intense UV illumination. Semicond. Sci. Technol. 31, 085014 (2016).

44 Grove, A. S. Physics and Technology of Semiconductor Devices 130-131 (Wiley: New York, USA, 1967)

45 Stoneham, A. M. Theory of Defects in Solids: Electronic Structure of Defects in Insulators and Semiconductors (Clarendon Press: Oxford, UK, 1975).

46 Punkkinen, M. P. J., Laukkanen, P., Kuzmin, M., Levamaki, H., Lang, J., Tuominen, M., Yasir, M., Dahl, J., Lu, S., Delczeg-Czirjak, E. K., Vitos, L. \& Kokko, K. Does Bi form clusters in $\mathrm{GaAs}_{1-x} \mathrm{Bi}_{x}$ alloys? Semicond. Sci. Technol. 29, 115007 (2014).

47 Yoshimoto, M., Itoh, M., Tominaga, Y. \& Oe, K. Quantitative estimation of density of Bi-induced localized states in $\mathrm{GaAs}_{1-x} \mathrm{Bi}_{x}$ grown by molecular beam epitaxy. J. Cryst. Growth 378, 73 (2013)

48 Bliss, D. E., Walukiewicz, W. \& Haller, E. E. Annealing of $\mathrm{As}_{\mathrm{Ga}}$-related defects in LT-GaAs: the role of gallium vacancies. J. Electron. Mater. 22, 1401 (1993).

49 Lochtefeld, A. J., Melloch, M. R., Chang, J. C. P. \& Harmon, E. S. The role of point defects and arsenic precipitates in carrier trapping and recombination in low-temperature grown GaAs. Appl. Phys. Lett. 69, 1465 (1996).

50 Fushimi, H. \& Wada, K. The presence of isolated hydrogen donors in heavily carbon-doped GaAs. J. Cryst. Growth 145, 420 (1994).

51 Lagowski, J., Kaminska, M., Parsey, J. M., Gatos, H. C. \& Lichtensteiger, M. Passivation of the dominant deep level (EL2) in GaAs by hydrogen. Appl. Phys. Lett. 41, 1078 (1982)

52 Capizzi, M., Coluzza, C., Frankl, P., Frova, A., Colocci, M., Gurioli, M., Vinattieri, A. \& Sacks, R. N. Picosecond spectroscopy of hydrogenated MBE-GaAs. Phys. B 170, 561 (1991).

53 Hung, W. K., Chern, M. Y. \& Chen, Y. F. Epitaxial $\mathrm{GaN}_{x} A s_{1-x}$ layer formed by pulsed-laser irradiation of GaAs in an ambient nitrogen gas. Semicond. Sci. Technol. 15, 892 (2000).

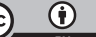

This work is licensed under a Creative Commons Attribution 4.0 International License. The images or other third party material in this article are included in the article's Creative Commons license, unless indicated otherwise in the credit line; if the material is not included under the Creative Commons license, users will need to obtain permission from the license holder to reproduce the material. To view a copy of this license, visit http:// creativecommons.org/licenses/by/4.0/

(C) The Author(s) 2017

Supplementary Information accompanies the paper on the NPG Asia Materials website (http://www.nature.com/am) 